\title{
Enantioseparation of Dansylated Amino Acids by Ligand-exchange Capillary Electrophoresis Using L-phenylalaninamide, L-lysine or L-threonine as Chiral Selector
}

\author{
Stefan Mohr, Johannes S. Hägele, and Martin G. Schmid* \\ Department of Pharmaceutical Chemistry, Institute of Pharmaceutical Sciences, \\ Karl-Franzens-University Graz, Universitätsplatz 1, A-8010 Graz, Austria
}

RECEIVED SEPTEMBER 30, 2010; REVISED NOVEMBER 15, 2010; ACCEPTED DECEMBER 2, 2010

\begin{abstract}
In recent years enantioseparation of both active pharmaceutical ingredients and bio molecules such as amino acids became more and more necessary because in most cases the two stereo forms exhibit different pharmacological effects. This article deals with the chiral separation of dansylated amino acids by ligand-exchange capillary electrophoresis using L-phenylalaninamide, L-lysine and L-threonine as chiral selectors. Experiments with different central metal ions such as $\mathrm{Cu}(\mathrm{II}), \mathrm{Co}(\mathrm{II}), \mathrm{Cd}(\mathrm{II}), \mathrm{Ni}(\mathrm{II})$ and $\mathrm{Zn}(\mathrm{II})$ were carried out. Optimal conditions were found out by studying the effect of the $\mathrm{pH}$ and the selector molarity on the chiral resolution. Best separation was obtained for the $\mathrm{Cu}(\mathrm{II}) / \mathrm{L}-\mathrm{lysine}$ complex, showing a chiral resolution up to 17 for Dns-DL-Met. (doi: 10.5562/cca1762)
\end{abstract}

Keywords: LECE, dansylated amino acids, CZE, chiral separation, ligand-exchange, capillary electrophoresis

\section{INTRODUCTION}

The development of enantiomer separation techniques has attracted great attention since it was investigated that in some cases only one enantiomer of a racemic drug mixture shows the desired pharmacological effect (eutomer). The other form (distomer) may not show any effect e.g. (R)-ibuprofen, ${ }^{1}$ unwanted side effects as it is the case with D-thyroxine, or in some cases even toxic effects e.g. D-DOPA. About half of the used drug substances are chiral and about $35 \%$ out of them are administered as pure enantiomers. ${ }^{2}$ Even if there are not that drastic effects of the distomer, it represents an unnecessary burden for the organism.

The chiral separation of underivatized and DnsAAs is of special interest not at least since it was postulated that, in contrary to former hypothesis, D-amino acids also occur in higher animals and not only in lower species. The D-forms can have physiological effects such as D-Ser and D-Asp or they can be related to pathophysiological processes, such as Alzheimer's disease, Parkinson's disease, schizophrenia and renal disease. ${ }^{3}$ AAs and their derivatives are used as building blocks for peptide synthesis or as drugs e.g. 3,4dihydroxyphenylalanine (L-DOPA) and L-Trp. Dansyla- tion of AAs is used on the one hand to label the Nterminal end of a peptide and on the other hand to simplify the detection of amino acids.

In recent decades multitudes of direct as well as indirect chiral separation techniques have been developed. In addition to HPLC and GC capillary electrophoresis turned out to be a powerful alternative with some unique advantages e.g. high peak efficiency, good compatibility with biological samples, short analysis times and the low consumption of buffer solutions. Even the flexibility in changing the method conditions played a considerable role in the rise of $\mathrm{CE}$ to one of the most spread separation techniques together with HPLC.

In most cases chiral separation in CE is performed by an enantioselective interaction of a so called chiral selector and the analyte ${ }^{4}$ but there are also some groups developing new chiral derivatization procedures applied in indirect separation techniques. ${ }^{5-7}$

In the direct separation mode different types of chiral selectors, such as cyclodextrines, macrocyclic antibiotics, carbohydrates, chiral crown ethers, calixarenes, proteins and chiral metal complexes (Ligand-exchange) are most commonly used as chiral selectors. ${ }^{8-12}$

The principle of ligand-exchange is based on the formation of diastereomeric ternary mixed metal com-

\footnotetext{
$\dagger$ Presented at the $10^{\text {th }}$ International Symposium and Summer School on Bioanalysis within the CEEPUS Network CII-HU-001004-0910, Zagreb, Croatia, July 2010.

* Author to whom correspondence should be addressed. (E-mail: martin.schmid@uni-graz.at)
} 
plexes between the chiral selector ligand and the analyte and was first introduced by Davankov and Roghozin in the late 1960 s-early 1970 s for conventional columns. ${ }^{13}$ Zare and co-workers transformed this principle to $\mathrm{CE}$ using histidine or aspartame- $\mathrm{Cu}(\mathrm{II})$ complexes for the resolution of racemic mixtures of Dns-AAs in the late 1980s. ${ }^{14}$ Schmid and Gübitz succeeded first in directly resolving underivatized AAs using L-Pro and L-Hypro as their $\mathrm{Cu}(\mathrm{II})$ complexes added to the electrolyte. ${ }^{15}$ Meanwhile a multitude of different chiral selectors for the resolution of AAs and Dns-AAs racemates by LE were introduced by different groups, namely, $\mathrm{Cu}(\mathrm{II})$ L-arginine, ${ }^{16} \mathrm{Zn}(\mathrm{II})$-L-arginine, ${ }^{17} \mathrm{Cu}(\mathrm{II})$-aspartame, ${ }^{18,19}$ $\mathrm{Cu}$ (II)-L-alaninamide, ${ }^{20} \mathrm{Cu}(\mathrm{II})-N, N$-didecyl-L-alanine, ${ }^{21,22} \mathrm{Cu}(\mathrm{II})$-L-histidine, ${ }^{14} \mathrm{Cu}(\mathrm{II})$-L-isoleucine, ${ }^{23}$ $\mathrm{Cu}$ (II)-L-lysine, ${ }^{24} \mathrm{Zn}$ (II)-L-lysine, ${ }^{25} \mathrm{Cu}(\mathrm{II})$-L-ornithine, ${ }^{26} \mathrm{Cu}(\mathrm{II})$-D-penicillamine ${ }^{\text {LE-MEKC }},{ }^{27} \mathrm{Zn}$ (II)-L-phenylalaninamide, ${ }^{28} \mathrm{Cu}$ (II)-L-phenylalaninamide, ${ }^{20} \mathrm{Cu}(\mathrm{II})-N$ (2-hydroxyoctyl)-L-4-hydroxyproline, ${ }^{29,30} \mathrm{Cu}(\mathrm{II})-\mathrm{L}-4-$ hydroxyproline, ${ }^{15,31-33} \mathrm{Cu}(\mathrm{II})-N$-(2-hydroxypropyl)-L-4hydroxyproline, ${ }^{29,30} \mathrm{Cu}(\mathrm{II})-\mathrm{L}-$ proline ${ }^{15,23}$ and $\mathrm{Cu}(\mathrm{II})-\mathrm{L}-$ prolinamide $^{20}$.

In this research, experiments with the three chiral selectors L-phenylalaninamide, L-lysine and L-threonine were performed under different conditions, to resolve Dns-AAs by LECE. For the optimization of the methods the effect of the $\mathrm{pH}$ value and the selector concentration on the resolution is shown. For the $\mathrm{Cu}$ (II)/L-lysine a validation referring to repeatability was carried out.

\section{EXPERIMENTAL}

\section{Instrumentation}

A fully automated ${ }^{3 \mathrm{D}} \mathrm{CE}$ system (Agilent Technologies, CA, USA) equipped with a diode array detector was used for the experiments. Measurements were performed in $50 \mu \mathrm{m}$ ID fused silica capillaries $(58.5 / 50 \mathrm{~cm}$ effective length) from Microquartz (Munich, Germany). Detection was performed via on-column measurements of the UV absorption at 208 and $254 \mathrm{~nm}$. Operation temperature was set to $25{ }^{\circ} \mathrm{C}$. Before measurement capillaries were washed with water, $0.2 \mathrm{~mol} \mathrm{dm}^{-3}$ $\mathrm{NaOH}$, water and electrolyte. Samples were injected hydrodynamically for $5 \mathrm{~s}$ at $10 \mathrm{mbar}$ unless indicated otherwise.

\section{Chemicals and Solutions}

All chemicals were of analytical grade. Dns-DL- $\alpha-A B A$, Dns-DL-Asp, Dns-DL-Glut, Dns-DL-Leu, Dns-DL-NLe, Dns-DL-Met, Dns-DL-Phe, Dns-DL-Thr, Dns-DL-Trp, Dns-DL-Val, Dns-DL-NVa, L-phenylalaninamide, L and D lysine $\mathrm{HCl}$ and L-threonine were purchased from Sigma-Aldrich Chemicals (St. Louis, MO, USA). Am- monium acetate, sodium acetate, $\mathrm{Cu}$ (II) sulfate, $\mathrm{Zn}$ (II) sulfate, Ni(II) sulfate, $\mathrm{Co}$ (II) sulfate and Cd(II) chloride were obtained from VWR (Darmstadt,Germany). Water was deionized and double distilled.

The electrolyte was prepared by dissolving a desired quantity of the chiral selector and the ionic additives in double-distilled water. The $\mathrm{pH}$ was adjusted depending on the buffer system with a suitable reagent. The solutions were degassed for 2 minutes by ultrasonification and filtered through a $0.45 \mu \mathrm{m}$ pore size Teflon filter (Schleicher and Schuell, Dassel, Germany) before use.

Sample solutions were prepared by dissolving the analytes $(1 \mathrm{mg} / \mathrm{ml})$ in a mixture of methanol/water $(1: 1)$.

\section{RESULTS AND DISCUSSION}

Enantioseparation in LECE is based on the formation of diastereomeric ternary mixed metal complexes between the chiral selector ligand and the analyte. Depending on the different complex stability constants of the two mixed complexes enantiomer resolution is reached. The following equilibria should be taken into account:

$$
\begin{aligned}
& \mathrm{Cu}(\text { L-selector })_{2}+\text { S-analyte } \rightleftarrows \\
&(\text { L-selector }) \mathrm{Cu}(\text { S-analyte })+\text { L-selector } \\
& \mathrm{Cu}(\text { L-selector })_{2}+\text { R-analyte } \rightleftarrows \\
&(\text { L-selector }) \mathrm{Cu}(\text { R-analyte })+\text { L-selector }
\end{aligned}
$$

The optimum $\mathrm{pH}$ for the complexation differs from chiral selector and the type of analyte. The correlation between the $\mathrm{pH}$ and the chiral resolution for different selectors is shown later.

\section{Use of L-phenylalaninamide as Chiral Selector}

L-phenyalaninamide was already used for the resolution of Dns-AAs by $\mathrm{Chen}^{34}$ with $\mathrm{Cu}(\mathrm{II})$ and by $\mathrm{Qi}^{28}$ with $\mathrm{Zn}(\mathrm{II})$ as central metal ion. For the following experiments a similar background electrolyte was chosen to guarantee adequate current. Ammonium acetate was replaced by sodium acetate. A chiral selector concentration of 10 mmol $\mathrm{dm}^{-3}$ and a selector to ion ratio of $2: 1$ was used. Using $\mathrm{Zn}(\mathrm{II})$ as central ion, Dns-DL-NLeu, Dns-DL-Nval, Dns-DL-Leu and Dns-DL- $\alpha$-ABA were resolved in addition to those Dns-AAs presented in the afore cited articles. With $\mathrm{Cu}(\mathrm{II})$ as metal ion no new analytes could be resolved. Table 1 shows the obtained results using $\mathrm{Zn}$ (II) as metal ion. In contrast to $\mathrm{Cu}(\mathrm{II}), \mathrm{Zn}$ (II) was used with negative voltage in order to detect the analytes. The change in the polarity was manifested in the enantiomer migration order (EMO). With $\mathrm{Zn}$ (II) the D-form migrates faster than the L-form, with $\mathrm{Cu}(\mathrm{II})$ it is the opposite. 
Table 1. Additionally separated Dns-DL-AAs using Zn(II)-Lphenylalaninamide as a chiral selector

\begin{tabular}{lcccc}
\hline & $t_{1} / \min$ & $t_{2} / \min$ & $\alpha$ & $R_{\mathrm{s}}$ \\
\hline Dns-DL- $\alpha-A B A$ & 17.26 & 17.32 & 1.004 & 0.6 \\
Dns-DL-Leu & 16.17 & 16.29 & 1.007 & 1.3 \\
Dns-DL-NLe & 19.61 & 19.90 & 1.015 & 2.9 \\
Dns-DL-NVa & 17.53 & 17.69 & 1.009 & 1.6 \\
\hline
\end{tabular}

Conditions: $10 \mathrm{mM}$ L-phenylalaninamide, $5 \mathrm{mM}$ zinc(II) sulfate, $5 \mathrm{mM}$ sodium acetate, $100 \mathrm{mM}$ boric acid; adjusted with $1 \mathrm{M}$ tris-solution to $\mathrm{pH} 8.2$; applied voltage: $23 \mathrm{kV}$ to anode; Injection: 10 mbar for $6 \mathrm{~s}$.

Copper and zinc are the most frequently used central ions but apart from those, other ions were investigated for their complex building ability. ${ }^{35}$ We examined the effect of $\mathrm{Ni}(\mathrm{II}), \mathrm{Cd}(\mathrm{II})$ and $\mathrm{Co}(\mathrm{II})$ on the resolution of Dns-AAs. Using Ni(II) as metal ion 7 out of 11 tested analytes could be resolved as it is shown in Table 2. For Dns-DL-Met, Dns-DL-Phe and Dns-DL-Trp the resolution was higher than 1.5.

Because Ni(II) was not used before as central ion in combination with phenylalaninamide the optimum $\mathrm{pH}$-value and selector concentration was to be found out. Figure 1 shows the effect of the $\mathrm{pH}$ on the resolution of Dns-DL-Trp. The higher the resolution the more stable is the complex at the specific $\mathrm{pH}$ value. The best resolution turned out to occur at a $\mathrm{pH}$ of 8.2 as it was used with $\mathrm{Cu}(\mathrm{II})$ and $\mathrm{Zn}(\mathrm{II})$.

The effect of the selector concentration is shown in Figure 2. The selector to metal ion ratio was set to 2:1 and the total molarity of selector plus metal ion was

Table 2. Enantioseparation of Dns-DL-AAs by Ni(II)-Lphenylalaninamide as a chiral selector

\begin{tabular}{lrrcc}
\hline & $t_{1} / \min$ & $t_{2} / \min$ & $\alpha$ & $R_{\mathrm{s}}$ \\
\hline Dns-DL- $\alpha-A B A$ & 17.53 & 17.64 & 1.006 & 0.7 \\
Dns-DL-Glut & 9.51 & 9.58 & 1.008 & 0.8 \\
Dns-DL-Leu & 20.76 & 20.91 & 1.007 & 0.7 \\
Dns-DL-NLe & 18.59 & 18.76 & 1.009 & 1.1 \\
Dns-DL-Met & 22.90 & 23.85 & 1.041 & 2.4 \\
Dns-DL-Phe & 18.60 & 18.83 & 1.013 & 2.0 \\
Dns-DL-Thr & 19.70 & - & 1.000 & - \\
Dns-DL-Trp & 24.94 & 25.25 & 1.012 & 1.8 \\
Dns-DL-Val & 18.90 & - & 1.000 & - \\
Dns-DL-NVa & 18.52 & 18.65 & 1.007 & 0.9 \\
\hline
\end{tabular}

Conditions: $10 \mathrm{mM}$ L-phenylalaninamide, $5 \mathrm{mM}$ nickel(II) sulfate, $5 \mathrm{mM}$ sodium acetate, $100 \mathrm{mM}$ boric acid; adjusted with $1 \mathrm{M}$ tris-solution to $\mathrm{pH} 8.2$; applied voltage: $23 \mathrm{kV}$ to anode; Injection: $10 \mathrm{mbar}$ for $6 \mathrm{~s}$.

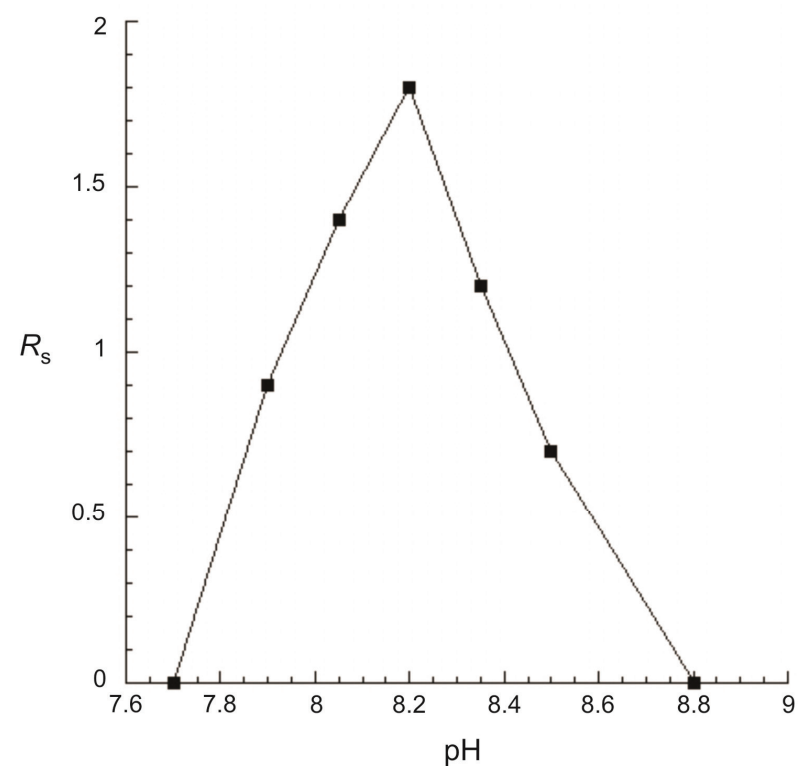

Figure 1. Effect of the $\mathrm{pH}$ value of the Ni(II)-L-phenylalaninamide complex on the resolution. Conditions: $10 \mathrm{mM} \mathrm{L}-$ phenylalaninamide, $5 \mathrm{mM}$ nickel(II) sulfate, $5 \mathrm{mM}$ sodium acetate, $100 \mathrm{mM}$ boric acid; $\mathrm{pH}$ adjusted with $1 \mathrm{M}$ trissolution; applied voltage: $23 \mathrm{kV}$ to anode; Injection: 10 mbar for $6 \mathrm{~s}$.

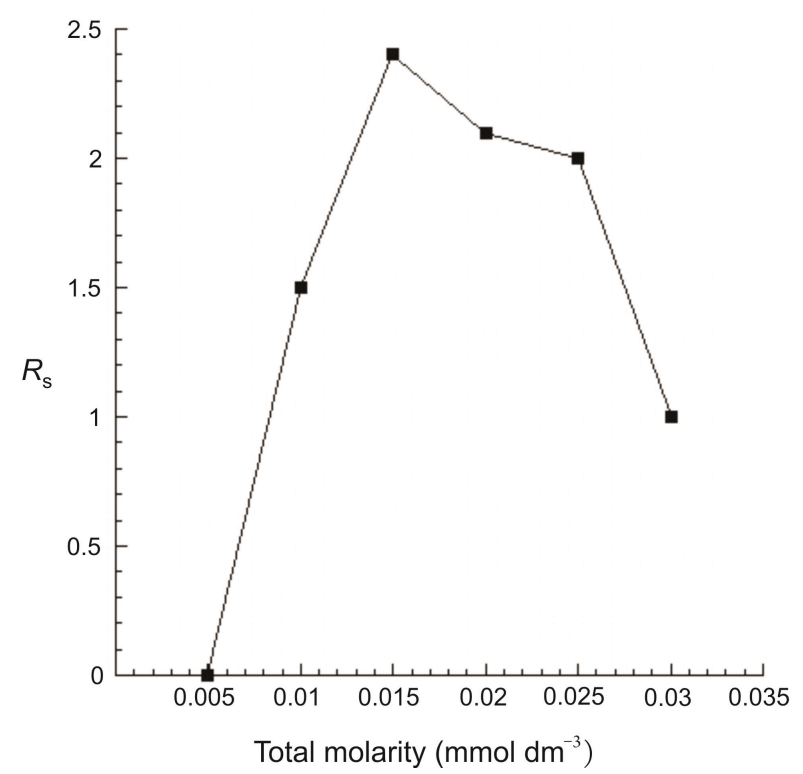

Figure 2. Effect of the total molarity of Ni(II)-Lphenylalaninamide complex. on the resolution. Conditions: L-phenylalaninamide / nickel(II) sulfate 2:1, $5 \mathrm{mM}$ sodium acetate, $100 \mathrm{mM}$ boric acid; adjusted with $1 \mathrm{M}$ tris-solution to $\mathrm{pH} 8.2$; applied voltage: $23 \mathrm{kV}$ to anode; Injection: 10 mbar for $6 \mathrm{~s}$.

changed. Best results were obtained at a total molarity of $15 \mathrm{mmol} \mathrm{dm}^{-3}$, which means that $10 \mathrm{mmol} \mathrm{dm}^{-3}$ selector and $5 \mathrm{mmol} \mathrm{dm}^{-3} \mathrm{Zn}$ (II) were used. The electronic source was set to positive mode and so the EMO 


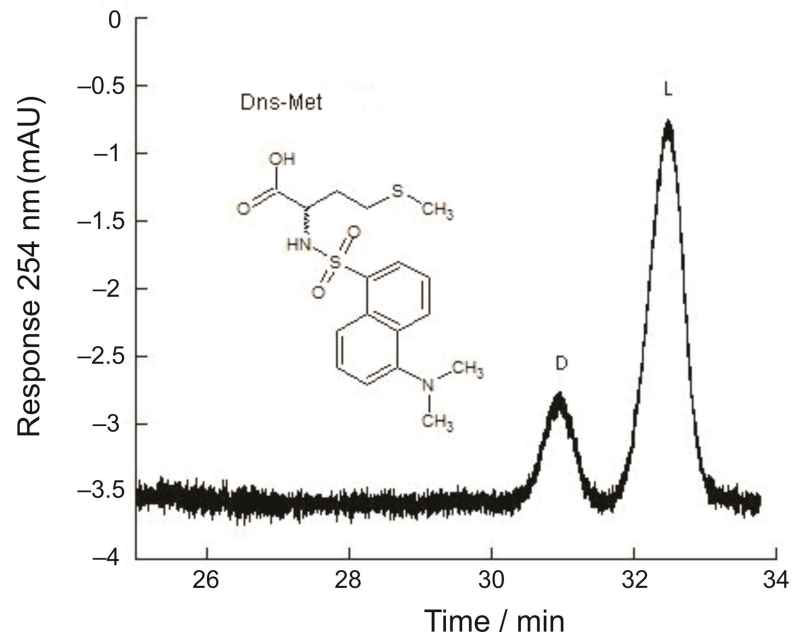

Figure 3. Determination of the EMO of Dns-DL-methionine spiked with L-enantiomer using L-phenylalaninamide as chiral selector. Conditions: $10 \mathrm{mM}$ L-phenylalaninamide, $5 \mathrm{mM}$ nickel(II) sulfate, $5 \mathrm{mM}$ sodium acetate, $100 \mathrm{mM}$ boric acid; adjusted with $1 \mathrm{M}$ tris-solution to $\mathrm{pH} 8.2$; applied voltage: 23 $\mathrm{kV}$ to anode; Injection: 10 mbar for $6 \mathrm{~s}$.

was D before L. Therefore this method is applicable for purity checking of Dns-L-AAs. The determination of the EMO is shown in Figure 3 for Dns-DL-Met.

The L-phenylalaninamide-Cd(II)-system showed chiral separation for Dns-DL-NVal, Dns-DL-NLeu and Dns-DL-Asp. Obviously it was the first time resolution of a racemic mixture of Dns-AAs was obtained with $\mathrm{Cd}(\mathrm{II})$ as central metal ion. With the metal ion $\mathrm{Co}$ (II) no analytes were separated.

\section{Use of L-lysine as Chiral Selector}

The suitability of lysine complexes for the chiral separation of underivatized amino acids was introduced by $\mathrm{Lu}^{24}$ for $\mathrm{Cu}$ (II) as central metal ion and by $\mathrm{Qi}^{25}$ for $\mathrm{Zn}$ (II) complexes. To our knowledge there is no publication that deals with the enantioseparation of derivatized amino acids using this selector-ion system.

The background electrolyte consisting of $25 \mathrm{mmol}$ $\mathrm{dm}^{-3}$ ammonium acetate was adopted from previous unpublished experiments with L-ornithin as chiral selector showing similar structure.

Copper(II) was used as central metal ion in a 1 to 2 ratio to the selector.

To optimize the conditions $\mathrm{pH}$ values from 5.1 to 9 were tested. Figure 4 shows the relation between the $\mathrm{pH}$ and the chiral resolution for the model substance Dns-DL-Trp. The use of L-Lys/Cu(II) showed a high resolution among the whole $\mathrm{pH}$ spectrum. Figure 4 and 5 show that even the poorest resolution for Dns-DL-Trp was higher than 10. Further the relation between the total molarity of selector plus copper(II) and the resolution was investigated as it is shown in Figure 5.

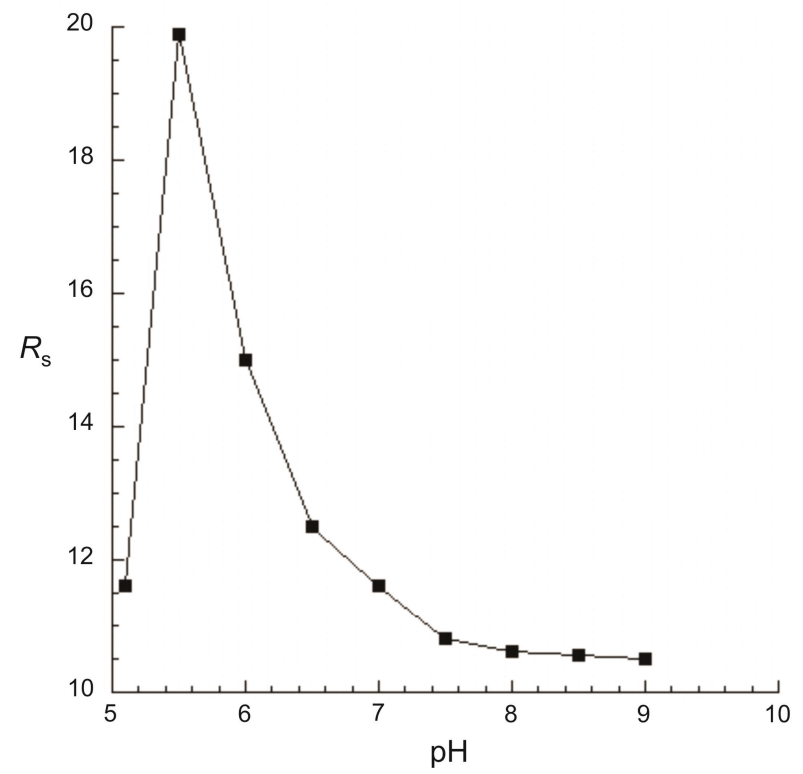

Figure 4. Correlation between the $\mathrm{pH}$ value and the resolution for the $\mathrm{Cu}(\mathrm{II})-\mathrm{L}-\mathrm{lysine}$ complex. Conditions: $10 \mathrm{mM} \mathrm{L}-l y s i n e$, $5 \mathrm{mM}$ copper(II) sulfate, $25 \mathrm{mM}$ ammonium acetate; $\mathrm{pH}$ adjusted with ammonia; applied voltage: $27 \mathrm{kV}$ to cathode; Injection: 15 mbar for $5 \mathrm{~s}$.

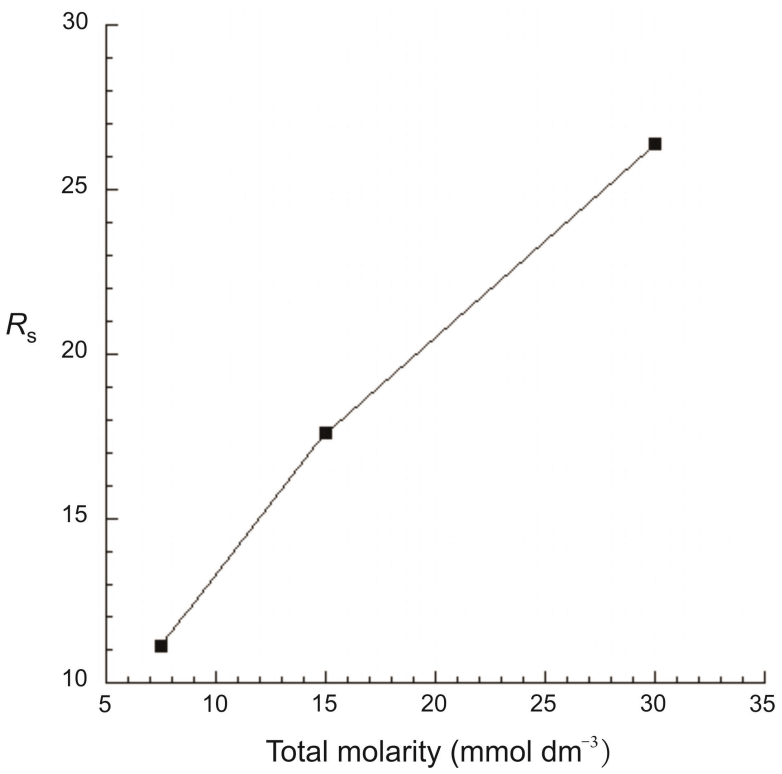

Figure 5. Correlation between the total molarity of $\mathrm{Cu}(\mathrm{II})-\mathrm{L}-$ lysine complex and the resolution. Conditions: L-lysine/ copper(II) sulfate 2:1, $5 \mathrm{mM}$ copper(II) sulfate, $25 \mathrm{mM}$ ammonium acetate; $\mathrm{pH} 5.5$ adjusted with ammonia; applied voltage: $27 \mathrm{kV}$ to cathode; Injection: 15 mbar for $5 \mathrm{~s}$.

Resolution increased with higher concentration of selector-copper(II) complex. With respect to migration time an electrolyte of $10 \mathrm{mmol} \mathrm{dm}^{-3}$ L-lysine and 5 mmol dm ${ }^{-3} \mathrm{Cu}(\mathrm{II})$ at $\mathrm{pH} 8.0$ was to screen a set of DnsAAs in further experiments. The repeatability of the 
Table 3. Repeatability data for retention time and resolution by means of Dns-DL-tryptophan

\begin{tabular}{lccc}
\hline & $t_{1} / \mathrm{min}$ & $t_{2} / \mathrm{min}$ & $R_{\mathrm{s}}$ \\
\hline Intraday $n=5$ & $11.23 \pm 0.58, \mathrm{RSD}=5.24 \%$ & $12.35 \pm 0.78 \mathrm{RSD}=6.29 \%$ & $11.12 \pm 0.91 \mathrm{RSD}=8.18 \%$ \\
Day-to-day $n=10$ & $11.43 \pm 0.84, \mathrm{RSD}=7.35 \%$ & $12.48 \pm 1.15, \mathrm{RSD}=9.23 \%$ & $11.42 \pm 1.29, \mathrm{RSD}=11.26 \%$ \\
\hline
\end{tabular}

Conditions: $10 \mathrm{mM}$ L-lysine, $5 \mathrm{mM}$ copper(II) sulfate, $25 \mathrm{mM}$ ammonium acetate; adjusted with ammonia to $\mathrm{pH} 5.5$; applied voltage: $27 \mathrm{kV}$ to cathode; Injection: 15 mbar for $5 \mathrm{~s}$.

method for the analyte Dns-DL-tryptophan is shown in Table 3.

With this method 10 out of 11 tested Dns-amino acids were separated. Results are shown in Table 4. The resolution values range from 3.6 for Dns-DL-Asp and 17.0 for Dns-DL-Met. A simultaneous chiral resolution of a mixture of Dns-DL-Asp, Dns-DL-Met, Dns-DL-Asp, Dns-DL- $\alpha$-ABA and Dns-DL-Leu was achieved within 30 minutes. (Figure 6)

Due to the faster migration of the $\mathrm{L}$ enantiomer this method is not suitable for purity studies of Dns-LAAs because most of the time the smaller peak of the Dimpurity may be overlapped by the L-peak. Simple change of the selector from L- to D-lysine inverts the EMO and purity check can be performed for Lenantiomers. (Figure 7)

\section{Use of L-threonine as Chiral Selector}

The last chiral selector tested in this study was L-Thr which was used successfully for enantioseparation of sympathomimetics and $\beta$-blockers by Hödl et $a l .{ }^{36}$ In this work L-Thr is shown to be applicable for the chiral resolution of Dns-AAs as well. In this case no testing of different metal ions was performed. An electrolyte consisting of $90 \mathrm{mmol} \mathrm{dm}^{-3} \mathrm{~L}-\mathrm{Thr}$ and $45 \mathrm{mmol} \mathrm{dm}^{-3}$ $\mathrm{Cu}$ (II)-sulfate was used at $\mathrm{pH} 8.2$. The previous results

Table 4. Enantioseparation of Dns-AAs using Cu(II)-L-lysine as a chiral selector

\begin{tabular}{lcccr}
\hline & $t_{1} / \min$ & $t_{2} / \min$ & $\alpha$ & \multicolumn{1}{c}{$R_{\mathrm{s}}$} \\
\hline Dns-DL- $\alpha-A B A$ & 16.29 & 18.55 & 1.289 & 11.2 \\
Dns-DL-Asp & 28.09 & 29.42 & 1.069 & 3.6 \\
Dns-DL-Leu & 23.28 & 27.52 & 1.289 & 15.0 \\
Dns-DL-NLe & 16.74 & 18.30 & 1.189 & 7.1 \\
Dns-DL-Met & 13.50 & 16.09 & 1.552 & 17.0 \\
Dns-DL-Phe & 14.85 & 17.14 & 1.392 & 10.6 \\
Dns-DL-Thr & 16.23 & 17.52 & 1.187 & 6.1 \\
Dns-DL-Trp & 11.09 & 12.22 & 1.453 & 10.8 \\
Dns-DL-Val & 33.26 & 35.76 & 1.104 & 5.9 \\
Dns-DL-NVa & 13.31 & 14.81 & 1.252 & 6.4 \\
\hline
\end{tabular}

Conditions: $10 \mathrm{mM}$ L-lysine, $5 \mathrm{mM}$ copper(II) sulfate, $25 \mathrm{mM}$ ammonium acetate; adjusted with ammonia to $\mathrm{pH}$ 8.0; applied voltage: $27 \mathrm{kV}$ to cathode; Injection: $15 \mathrm{mbar}$ for $5 \mathrm{~s}$. with the other two chiral selectors show that a $\mathrm{pH}$ of about 8.0 is suitable for the complex formation of Dns-

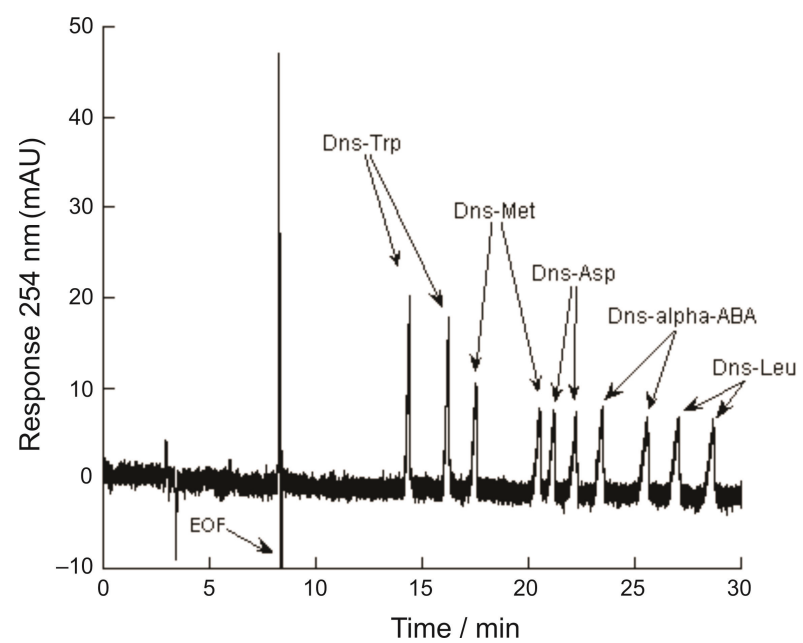

Figure 6. Simultaneous chiral separation of Dns-DL-Asp, DnsDL-Met, Dns-DL-Asp, Dns-DL- $\alpha-A B A$ and Dns-DL-Leu with Llysine as chiral selector. Conditions: $10 \mathrm{mM}$ L-lysine, $5 \mathrm{mM}$ copper(II) sulfate, $25 \mathrm{mM}$ ammonium acetate, adjusted with ammonia to $\mathrm{pH} 5.5$; applied voltage: $27 \mathrm{kV}$ to cathode; Injection: 10 mbar for $5 \mathrm{~s}$.

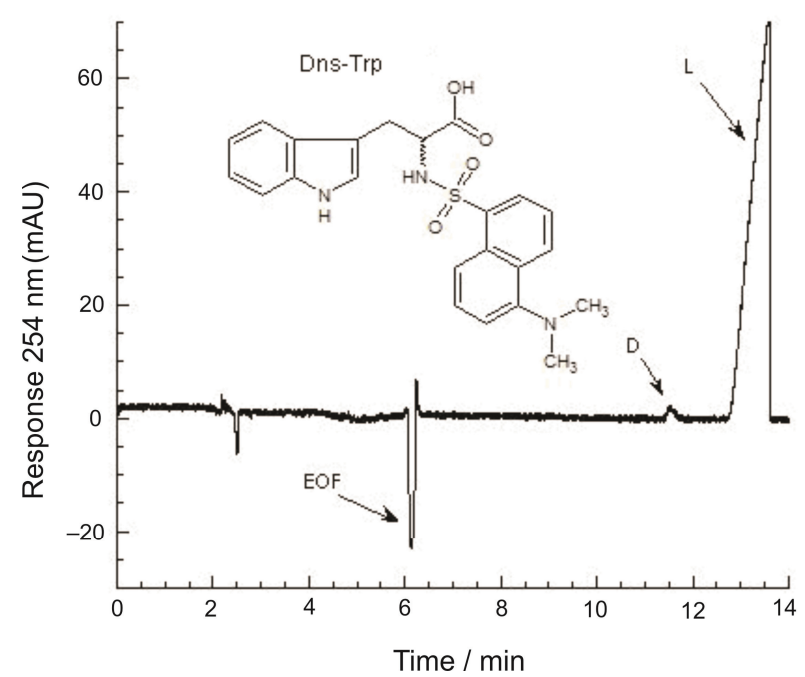

Figure 7. Purity check of Dns-L-tryptophan containing 3,5\% D-tryptophan with L-lysine as chiral selector. Conditions: 10 $\mathrm{mM}$ L-lysine, $5 \mathrm{mM}$ copper(II) sulfate, $25 \mathrm{mM}$ ammonium acetate, adjusted with ammonia to $\mathrm{pH} 5.5$; applied voltage: 27 $\mathrm{kV}$ to cathode; Injection: 10 mbar for $5 \mathrm{~s}$. 
Table 5. Enantioseparation of Dns-AAs using Cu(II)-Lthreonine as a chiral selector

\begin{tabular}{lcccc}
\hline & $t_{1} / \min$ & $t_{2} / \min$ & $\alpha$ & $R_{\mathrm{s}}$ \\
\hline Dns-DL-Glut & 40.050 & 41.430 & 1.052 & 2.9 \\
Dns-DL-Met & 20.965 & 21.105 & 1.019 & 1.2 \\
Dns-DL-Phe & 21.390 & 21.684 & 1.039 & 2.2 \\
Dns-DL-Trp & 26.656 & 28.104 & 1.103 & 5.7 \\
\hline
\end{tabular}

Conditions: $90 \mathrm{mM}$ L-threonine, $45 \mathrm{mM}$ copper(II) sulfate; adjusted with ammonia to $\mathrm{pH} 8.0$; applied voltage: $10 \mathrm{kV}$ to cathode; Injection: $10 \mathrm{mbar}$ for $5 \mathrm{~s}$.

AAs and additionally the EOF is relatively strong which results in shorter retention times. In total 4 out of 11 tested Dns-AAs were separated with this selector as it is shown in Table 5. Noticeable are the long migration times of the glutamic acid enantiomers. Because of the two carboxylic groups the molecule seems to be slightly negatively charged and tends to migrate opposite to the EMO to the anode. The EMO turned out to be $\mathrm{L}$ before D. The optimization of the method including $\mathrm{pH}$ value and selector-concentration will be subject to further investigations.

\section{CONCLUSION}

The suitability of L-phenylalaninamide, L-lysine and Lthreonine as chiral selectors in LECE with different central metal ions was shown. The L-phenylalaninamide/Ni(II) complex was applicable for the enantioseparation of 8 Dns-AAs and even with Cd(II) 3 Dns-AAs were resolved. With L-Lys/Cu(II) 10 out of 11 Dns-AAs were separated with high resolution compared to the other selector/metal complexes. Additionally 5 DnsAAs were separated simultaneously. L-Thr which up to now has been used only for the chiral separation of sympathomimetics and $\beta$-blockers showed an effect on the chiral resolution of Dns-AAs with $\mathrm{Cu}(\mathrm{II})$ as metal ion as well.

\section{ABBREVIATIONS}

AA, amino acid; LECE, ligand-exchange capillary electrophoresis; Dns-AAs, dansylated amino acids

\section{REFERENCES}

1. C. S. Chen, W.R. Shieh, P. H. Lu, S. Harriman, and C. Y. Chen, Biochim. Biophys. Acta 1078 (1991) 411-417.

2. J. S. Millership and A. Fitzpatrick, Chirality 5 (1993) 573-576.

3. K. Hamase, A. Morikawa, and K. Zaitsu, J. Chromatogr. B
Analyt. Technol. Biomed. Life Sci. 781 (2002) 73-91.

4. B. Chankvetadz and G. Blaschke, J. Chromatogr. A 906 (2001) 309-363.

5. J. Cheng and J. Kang, Electrophoresis 27 (2006) 865-871.

6. S. Zhao, R. Zhang, H. Wang, L. Tang, and Y. Pan, J. Chromatogr. B Analyt. Technol. Biomed. Life Sci. 833 (2006) 186-190.

7. S. Zhao, H. Wang, R. Zhang, L. Tang, and Y. M. Liu, Electrophoresis 27 (2006) 3428-3433.

8. G. Gübitz and M. G. Schmid, Electrophoresis 28 (2007) 114 126.

9. B. Preinerstorfer, M. Lammerhofer, and W. Lindner, Electrophoresis 30 (2009) 100-132.

10. B. Chankvetadze, J. Chromatogr. A 1168 (2007) 45-70; discussion 44.

11. G. Gübitz and M. G. Schmid, Mol. Biotechnol. 32 (2006) 159180 .

12. G. Gübitz and M. G. Schmid, J. Chromatogr. A 1204 (2008) $140-156$.

13. V. A. Davankov and S. V. Rogozhin, J. Chromatogr. 60 (1971) 280-283.

14. E. Gassmann, J. E. Kuo, and R. N. Zare, Science 230 (1985) 813-814.

15. M. G. Schmid and G. Gübitz, Enantiomer 1 (1996) 23-27.

16. Z. Yuan, L. Yang, and S. Zhang, Electrophoresis 20 (1999) 1842-1845.

17. L. Qi, Y. Chen, M. Xie, Z. Guo, and X. Wang, Electrophoresis 29 (2008) 4277-4283.

18. P. Gozel, E. Gassman, H. Michelsen, and R. N. Zare, Anal. Chem. 59 (1987) 44-49.

19. B. Soontornniyomkij, K. Scandrett, and D. J. Pietrzyk, J. Liq. Chromatogr. R T 21 (1998) 2245-2263.

20. Z. Chen, M. Niitsuma, T. Nakagama, K. Uchiyama, and T. Hobo, J. Sep. Sci. 25 (2002) 1197-1201.

21. A. S. Cohen, A. Paulus, and B. L. Karger, Chromatographia 24 (1987) 15-24.

22. N. G. Sundin, T. M. Dowling, N. Grinberg, and G. Bicker, Journal of Microcolumn Sep. 8 (1996) 323-329.

23. A. Karbaum and T. Jira, J. Chromatogr. A 874 (2000) 285-292.

24. X. Lu, Y. Chen, L. Guo, and Y. Yang, J. Chromatogr. A 945 (2002) 249-255.

25. L. Qi, Y. Han, M. Zuo, and Y. Chen, Electrophoresis 28 (2007) 2629-2634.

26. Z. X. Zheng, Y. Wei, and J. M. Lin, Electrophoresis 26 (2005) 1007-1012.

27. Z. X. Zheng, J. M. Lin, F. Qu, and T. Hobo, Electrophoresis $\mathbf{2 4}$ (2003) 4221-4226.

28. L. Qi and G. Yang, J. Sep. Sci. 32 (2009) 3209-3214.

29. A. Vegvari, M. G. Schmid, F. Kilar, and G. Gübitz, Electrophoresis 19 (1998) 2109-2112.

30. M. G. Schmid, R. Rinaldi, D. Dreveny, and G. Gübitz, J. Chromatogr. A 846 (1999) 157-163.

31. Z. Chen, J.-M. Lin, K. Uchiyama, and T. Hobo, J. Chromatogr. A 813 (1998) 369-378.

32. Z. Chen, J. Lin, K. Uchiyama, and T. Hobo, Chromatographia 49 (1999) 436-443.

33. Z. Chen, J. Lin, K. Uchiyama, and T. Hobo, Anal. Sci. 16 (2000) 131-137.

34. Z. Chen and T. Hobo, Anal. Chem. 73 (2001) 3348-3357.

35. H. Hödl, M. G. Schmid, and G. Gübitz, J. Chromatogr. A 1204 (2008) 210-218.

36. H. Hödl, A. Krainer, K. Holzmuller, J. Koidl, M. G. Schmid, and G. Gübitz, Electrophoresis 28 (2007) 2675-2682. 